\title{
Generational Aspects of Medicare
}

\author{
David M. Cutler and Louise Sheiner ${ }^{*}$
}

\begin{abstract}
This paper examines the generational aspect of the current Medicare system and some stylized reforms. We find that the rates of return on Medicare for today's workers are higher than those for Social Security and that the Medicare system is shifting a greater share of the burden on future workers than is Social Security. Nonetheless, the rates of return on Medicare, using the Medicare Trustees assumptions, are still not that high--roughly 2 percent for today's youngest workers. But forecasting future Medicare expenditures is quite difficult. Under an alternative higher-cost baseline, which we consider plausible, rates of return for today's youngest workers will exceed 3 percent. Putting Medicare on a sustainable basis by raising the payroll tax or reducing benefits would greatly reduce the rate of return for today's workers. Under the Trustees assumptions, for example, the payroll tax would have to be increased by 2.0 percent of payroll to put the Medicare system in balance in perpetuity. This policy would reduce the rate of return on today's youngest workers to about 1.3 percent.
\end{abstract}

* Cutler: Department of Economics, Harvard University, Cambridge, MA 02138, dcutler@harvard.edu; Sheiner: Board of Governors of the Federal Reserve System, Mail Stop 83, Washington, DC 20551, lsheiner@firb.gov. We are grateful to the National Institutes on Aging for research support. The views expressed are entirely our own and not necessarily those of the members or staff of the Federal Reserve Board. 
Long-term financial imbalances in the Medicare system make some sort of Medicare reform inevitable. But while the need to reform Medicare is widely acknowledged, understanding about the impact of proposed reforms - or even the current system - is limited. How much is Medicare worth to people? Which generations can reasonably be charged more or receive less in Medicare benefits? These questions have been explored at great length for the Social Security program, but the Medicare program has not drawn similar attention.

Analyzing the consequences of Medicare is difficult because Medicare is more than a cash transfer program. Unlike Social Security, which provides cash income, Medicare is a health insurance program, and the benefits of an insurance policy may differ from the cash transfer it makes. Still, understanding the dollar flows is a natural first step in Medicare reform. In this paper, we examine the generational aspect of the current Medicare system and some stylized reforms. ${ }^{1}$

\section{Intergenerational Redistribution in the Medicare Program}

To calculate Medicare returns by cohort, we begin with past and expected future Medicare spending by year. Our baseline assumption is the intermediate projections from the Medicare actuaries. We combine the overall spending data with data on age-specific Medicare costs to allocate Medicare expenditures, by year, across people of different cohorts. Since we are interested primarily in the distribution of resources between the elderly and non-elderly populations, we factor out Medicare spending on the non-aged, disabled population. We assume that after 1996, the last year of data, relative spending by age remains constant.

Medicare funding comes from three sources. A dedicated payroll tax is used to fund Part A, 
or Hospital Insurance, benefits. We distribute total HI payroll tax revenues using historical data on median earnings and the number of workers by age. For projections, we hold labor force participation rates and relative earnings by age constant at their 1995 values. Part B services are financed by beneficiary premiums ( 25 percent) and general revenues ( 75 percent). We follow current law and assume that Part B premiums will remain equal to 25 percent of Part B program costs. ${ }^{2}$ General revenue financing is distributed on the basis of personal income taxes. We impute tax payments using information on earnings by age from various March Current Population Surveys combined with the distribution of income taxes by adjusted gross income. Again, we assume that relative tax payments by age remain constant after 1999 .

The top row of Table 1 reports baseline estimates of Medicare internal rates of return by cohort. Figure 1 shows the net benefits per person reaching age 65 for cohorts born between 1890 and 1980, assuming a 3 percent real discount rate. ${ }^{3}$ The internal rate of return is highest for the oldest cohort and falls over time. The oldest two cohorts received substantial Medicare benefits ( $\$ 10,000$ and $\$ 25,000$ per person reaching age 65 in 2000 dollars), but paid very little for them; their rates of return are extremely high and are thus not reported. The first cohort with any substantial Medicare contribution, the 1910 cohort, still had a rate of return of 28 percent. By the 1950 cohort - the first one to pay payroll and income taxes throughout their life - the rate of return is expected to be 3.4 percent. And for the cohort entering the labor force today (the 1980 cohort), the rate of return is expected to be 2.2 percent.

In contrast to uniformly declining internal rates of return, the net benefit has an inverse- $\mathrm{U}$ shape. The highest net benefits are for the cohorts born in 1920 and 1930 and thus reaching age 65 within the past 15 years. These groups receive about $\$ 50,000$ net per person reaching age 65 in 2000 
dollars - about $\$ 70,000$ to $\$ 90,000$ of benefits offset by $\$ 20,000$ to $\$ 40,000$ of payments. The tax payments for these groups are high, but rapid increases in Medicare spending between younger and older ages raise the transfer from the system. By contrast, according to calculations by Dean Leimer (1994), the cohorts with the highest net wealth from Social Security were those born around 1910. The relatively high net benefits to more recent cohorts in Medicare reflects the fact that Medicare did not begin until 1965, and that medical expenditures have increased substantially over time.

Compared to Social Security, the returns on Medicare are very high. As shown in the last row of Table 1, Leimer (1994) estimates that Social Security rates of return were 8.4 percent for the 1910 cohort, 2.2 percent for the 1950 cohort, and 1.9 percent for the 1980 cohort. All of these are below the equivalent values for Medicare. But as with Social Security, the Medicare return is falling over time.

In steady state, of course, the rate of return to any pay-as-you-go system must equal the growth of aggregate income, which the social security actuaries expect to be about 1 percent per year. The fact that Medicare returns are above that reflects the fact that the system is not in actuarial balance. Eventually, rates of return on Medicare will have to fall.

Even with this imbalance, however, the Medicare returns are low in comparison to rates of return available on private securities. Three factors explain these relatively low returns. First, premium payments and general revenues increase automatically with health care costs. Second, life expectancy improvements in the baseline scenario are not very large. The current forecast projects life expectancy at birth rising from its current 76 years to 82 years over the next 75 years, not reaching levels currently attained in other countries until the middle of the next century. Third, and most important, the baseline growth of Medicare costs is not particularly rapid. In the actuary's 
intermediate forecast, real Medicare spending per beneficiary rises by 1.1 percent per year between 2000 and 2075, virtually the same rate as real GDP growth per worker. As shown in figure 2, this is a substantial reduction in growth forecasts from just a few years ago.

Long-term health spending forecasts are particularly problematic because public policy and private markets for medical services are changing so rapidly, and because small changes in growth rates, when compounded, can make huge differences in expected outlays. The actuaries have long assumed that after 25 years, Medicare spending per unit of service would grow no more rapidly than average hourly earnings. The short-term projections changed so rapidly because Medicare cost growth has been low in recent years. The Balanced Budget Act of 1997 made significant cuts in Medicare payments. ${ }^{4}$ In addition, there was a well-publicized crackdown on fraud in the program, and the overall growth of medical costs has slowed as well. All of these factors contributed to very low growth of Medicare costs in the past two years and, in the most recent forecasts, are expected to continue.

To examine the sensitivity of the rate of return estimates to these differing assumptions, we consider an alternative scenario for life expectancy and medical care cost growth. We assume that from 2000 to 2020, medical care cost growth increases by an additional 2.6 percent per year - the average differential between the growth of real, per person medical costs and real, per person GDP between 1960 and 1997. We also employ the mortality rates in the actuary's high-cost scenario to forecast the elderly population. Reducing mortality rates has two offsetting effects on spending. One the one hand, it implies more rapid growth of the elderly population, and particularly the oldestold (above 85) population than in the baseline forecast, thus raising Medicare costs. On the other hand, since fewer people die at any age and medical spending near death is substantially higher than 
in periods farther away from death, age-specific medical costs decline with increased mortality (Cutler and Sheiner, 2000). The reduction in age-specific medical costs offsets about half of the increase in spending that would be predicted were age-specific spending to remain the same.

The fourth row of table 1 shows rates of return under this alternative scenario, and Figure 1 shows the net benefit, assuming a 3 percent discount rate. Both rates of return and net benefits rise for recent cohorts. For the 1980 cohort, the increase in benefits from Medicare is about $\$ 50,000$, and the rate of return increases by nearly 1 percentage point.

\section{Simulating Policy Changes}

The scenarios we have presented are not sustainable. While Part B services have an automatic claim on general revenues, the Hospital Insurance trust fund for Part A does not. Using a 3 percent real rate of return (the return assumed by the actuaries), the Hospital Insurance trust fund runs a deficit of 2.0 percent of payroll in perpetuity under the baseline assumptions and 5.1 percent of payroll under the higher-cost alternative. To understand what balancing the deficit implies, we examine the impact of two policies that would eliminate the long-run trust fund deficit: raising the payroll tax and cutting benefits. In each case, the change begins in 2000 and continues indefinitely. The benefit cut needed is 38 percent in the baseline scenario and 61 percent in the high-cost alternative. ${ }^{5}$ Both of these solutions involve pre-funding: money is raised today, when the system is in balance, and invested for the future, when the system will be out of balance. Nonetheless, even under these alternatives, today's workers are better off than tomorrow's, because the income tax revenues used to finance Part B are growing faster than wages. ${ }^{6}$

Table 1 and Figure 1 show the internal rate of return and net benefits for different cohorts 
under these scenarios. These two policies have different effects on the intergenerational distribution from the program. The benefit cut has a substantially larger impact on current middle-aged cohorts and a smaller impact on future generations. Under the high-cost alternative, for example, the 1940 cohort receives about $\$ 75,000$ less under the benefit cut than under the payroll tax increase, while the 1980 cohort is $\$ 100,000$ richer if benefits are cut than if payroll taxes are raised. The difference between these policies is attributable to their effect on those who have largely finished paying into the system. Cohorts nearing retirement age fare much worse when benefits are cut than when payroll taxes are increased. Future generations, who must make up the difference, fare just the opposite.

In both of these scenarios, the net benefit to currently young and future generations is negative. This is directly related to the pay-as-you-go nature of the program; any pay-as-you-go system results in negative net transfers if the discount rate (the private rate of return to saving) exceeds the growth of real income.

\section{Discussion}

Despite the rapid increases in Medicare spending over the past 30 years, the rates of return on Medicare show the same pattern as those from Social Security, with earlier generations of workers getting high rates of return, and current generations getting relatively low returns. The somewhat higher rate of return to Medicare than to Social Security suggests that past analyses of generational equity that focus only on Social Security are somewhat misleading. Still, even were Social Security and Medicare to be considered jointly, one would not conclude that the fiscal balance is generous to current young and future generations.

Under the baseline assumptions, today's older workers are expected to get more out of 
Medicare than they paid in, using a 3 percent discount rate. Today's youngest workers are receiving more than the steady-state internal rate of return (about 1 percent), indicating that the burden on future generations is growing. Under the high-cost alternative, which we consider to be at least a plausible downside risk, even today's youngest workers are receiving returns slightly higher than 3 percent, indicating that the system's burden on future generations is increasing even more rapidly.

There is no reason that public policy should necessarily provide the same rate of return to all generations (Elmendorf and Sheiner, 1999). But should society want to equalize returns across cohorts, the choice is between cutting benefits, raising taxes in the future, or pre-funding revenues. To evaluate these alternatives, one needs to consider more than just the generational consequences of these changes. It is also important to determine whether Medicare provides benefits worth their cost.

Suppose, for example, that Medicare benefits were cut by 40 to 60 percent - the benefit cuts needed to guarantee fiscal balance. If people would save privately the amount that Medicare would have provided and could purchase insurance to supplement the benefits lost by Medicare, the only consequences would be the transfer of generational resources. But, private markets for health insurance may not work that well, and reductions in Medicare could lead to reductions in the elderly's utilization of medical services. ${ }^{7}$

The welfare implications of reducing medical utilization depends on the value of additional medical care spending for the elderly. Evidence here is mixed: some studies suggests that the average returns to medical care spending for the elderly are high; at the same time, however, the marginal return to additional spending appears to be quite low (Cutler, 2000). ${ }^{8}$ How a change in benefits would translate into health impacts for the elderly is thus unclear. Understanding the 
consequences of Medicare for overall medical care utilization of the elderly is an important issue in determining how to address the generational imbalances in the Medicare system.

\section{References}

Cutler, David (2000). "Walking the Tightrope on Medicare Reform", forthcoming, Journal of Economic Perspectives.

Cutler, David and Louise Sheiner (2000) "Demographic and Medical Care Spending: Standard and non-Standard Effects," forthcoming in Alan Auerbach, ed., Demographics and Fiscal Policy, Cambridge, MA: MIT Press.

Elmendorf, Douglas and Louise Sheiner (1999). ”Should America Save for its Old Age? Population Aging, National Saving, and Fiscal Policy", Working Paper.

Gokhale, Jagadeesh and Laurence J. Kotlikoff. (1998). "Medicare from the Perspective of Generational Accounting”, NBER Working Paper 6595.

Leimer, Dean R. (1994). “Cohort-Specific Measures of Lifetime Net Social Security Transfers", Social Security Administration, Office of Research and Statistics Working Paper Series, Number 59.

McClellan, Mark and Jonathan Skinner (1997), "The Incidence of Medicare”, NBER Working Paper No. 6013.

Steuerle, C. Eugene and Jon M. Bakija (1994), Retooling Social Security for the $21^{\text {st }}$ Century, The Urban Institute Press, Washington, D.C. 
Table 1: Internal Rates of Return to Medicare

\begin{tabular}{lcccccccc}
\hline & \multicolumn{7}{c}{ Cohort Born In } \\
\cline { 2 - 9 } & 1910 & 1920 & 1930 & 1940 & 1950 & 1960 & 1970 & 1980 \\
\hline Baseline & $27.6 \%$ & $12.1 \%$ & $7.0 \%$ & $4.6 \%$ & $3.4 \%$ & $2.8 \%$ & $2.5 \%$ & $2.2 \%$ \\
Raise HI tax by 2.0 percentage points & 27.6 & 12.1 & 7.0 & 4.5 & 3.0 & 2.2 & 1.6 & 1.3 \\
Cut benefits by 38 percent & 27.6 & 11.6 & 5.5 & 3.0 & 2.1 & 1.7 & 1.4 & 1.3 \\
Higher-Cost Alternative & 27.6 & 12.2 & 7.7 & 5.9 & 4.8 & 4.1 & 3.5 & 3.1 \\
Raise HI tax by 5.2 percentage points & 27.6 & 12.2 & 7.6 & 5.7 & 4.1 & 2.8 & 1.9 & 1.5 \\
Cut benefits by 61 percent & 27.6 & 11.4 & 4.9 & 2.8 & 2.2 & 1.9 & 1.6 & 1.4 \\
OASI Rate of Return & 8.4 & 5.7 & 4.0 & 2.7 & 2.2 & 1.8 & 1.9 & 1.9 \\
\hline Note: The last row is from Leimer (1994). & & & & & & & & \\
\hline
\end{tabular}

Figure 1: Net Benefits from Medicare, by Cohort

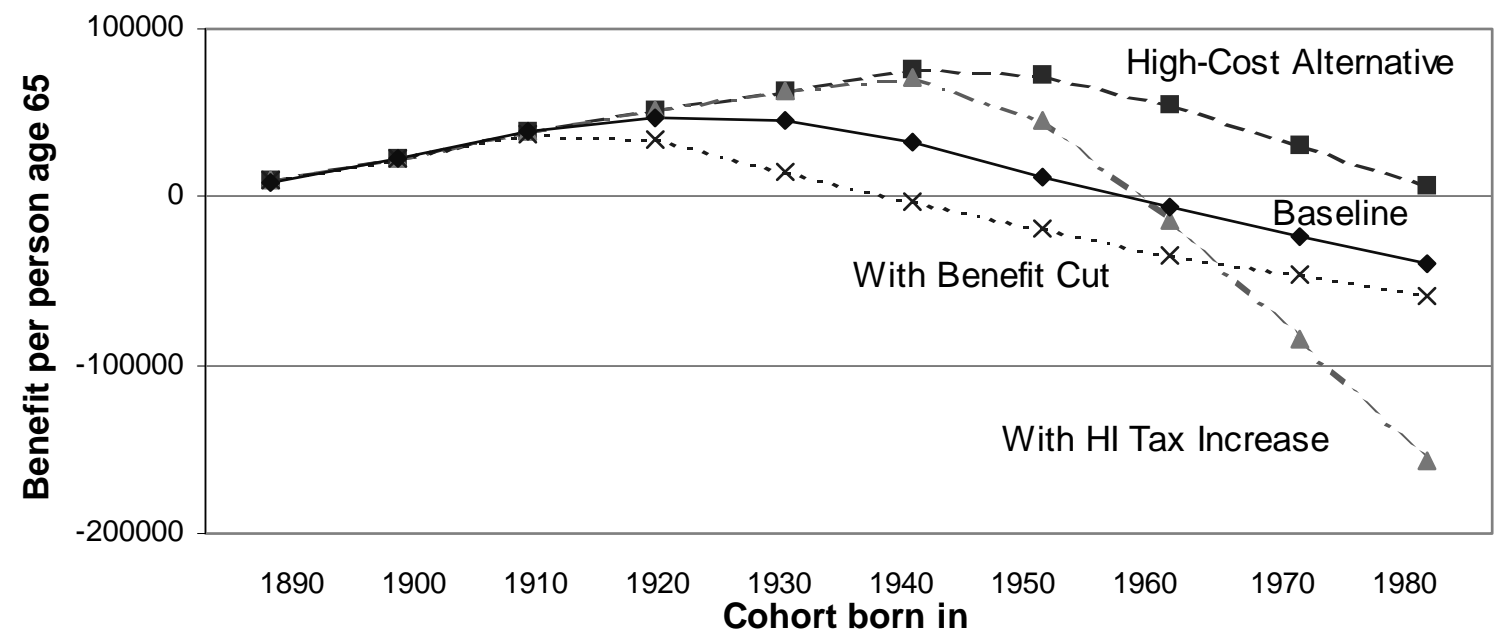

Figure 2: Growth of Real Medicare Spending per Beneficiary

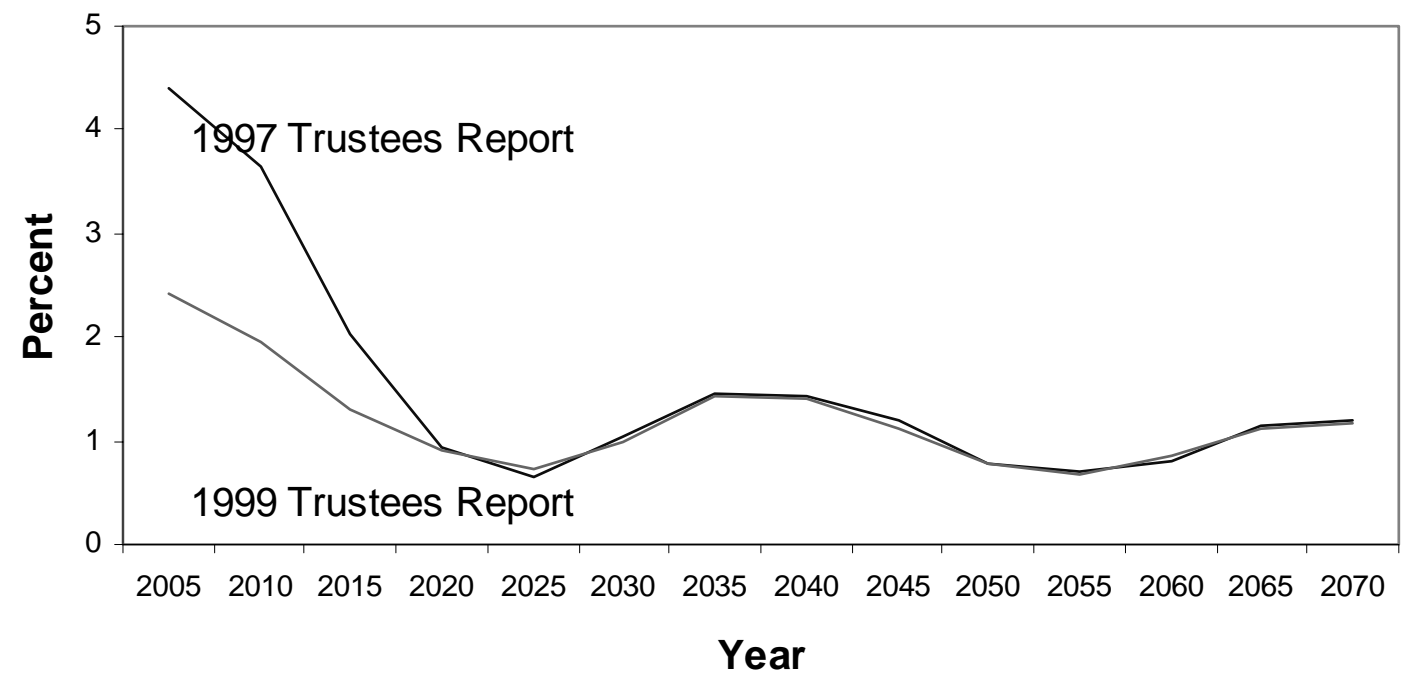




\section{Endnotes}

1. C. Eugene Steurele and Jon M. Bakija (1994), Congressional Budget Office (1997), and Jagadeesh Gokhale and Laurence J. Kotlikoff (1998) have also examined intergenerational aspects of the Medicare program.

2. Medicaid pays the Part B premium for low-income Medicare beneficiaries. We consider that payment to be a Medicaid benefit, and still credit each beneficiary with making a Part B payment. 3. This is the return used by the program actuaries. This return is likely too low. Doug Elmendorf and Sheiner (1999) argue that the average rate of return on capital is closer to 6 percent. The net benefits are lower with a higher value but the pattern of net benefits across cohorts is similar. 4. Indeed, spending fell sufficiently far that in 1999 Congress passed legislation to undo some of the Act's cuts. The actuaries are likely to increase the growth of Medicare in the 2000 Trustees' reports.

5. The benefit cuts are substantial because income taxes and Part B premiums by law are reduced along with Part $\mathrm{B}$ costs. If these amounts continue to be raised and placed in the HI trust fund, the required benefit cut would be smaller. An alternative reform is to increase income taxes. A tax increase of 2.5 percent of GDP is needed in the high-cost scenario. The generational consequences of this change are similar to the increase in HI payroll taxes.

6. An alternative scenario would fix Part B income taxes as a share of GDP, and raise payroll taxes enough to cover both the future Part A and Part B imbalances. To achieve sustainability under this scenario, payroll taxes would have to increase by 4.1 percent of payroll in the baseline, and 9.4 percent in the high-cost alternative. The internal rate of rate for today's youngest workers would fall to the sustainable level of about 1.1 percent.

7. Mark McClellan and Jonathan Skinner (1997) show that health insurance among the elderly was very poor prior to Medicare. 
8. Life expectancy among the elderly has increased by 2.4 years since 1960 , while the increase in Medicare spending as of age 65 has been only $\$ 56,000$. Thus, assuming the value of a life-year is about $\$ 100,000$, if at least one-quarter of the increase in life expectancy results from Medicare, increased Medicare spending is worth the cost. 